\title{
ÚLTIMA FASE DEL REPARTIMIENTO DE LA HUERTA DE MURCIA \\ (1286-1331)
}

Juan Torres Fontes

Universidad de Murcia

\section{RESUMEN}

El proceso de asentamiento castellano en Murcia fue largo y laborioso. La complejidad de la conquista, donde el elemento mudéjar juega un importante papel, convierte a la huerta murciana en uno de los mejores reflejos para observar esos cambios. Este trabajo se centra en la fase final del asiento y ocupación de la huerta murciana coincidiendo con los difíciles años del final del siglo XIII y primeras décadas del XIV.

PALABRAS ClAVE: Murcia, repartimiento, mudéjares, huerta.

\section{ABSTRACT}

The process of Castilian establishment in Murcia was long and laborious. The complexity of the conquest, where the Mudejar element plays an important paper, it transforms to the vegetable garden murciana into one of the best reflections to observe those changes. This work is centered in the final phase of the seat and occupation of the vegetable garden murciana coinciding with the difficult years of the end of the XIII century and first decades of the XIV one.

KEY WORDS: Murcia, distribution of lands, Mudejar, vegetable garden. 
Al publicar en 1971 mi estudio sobre el Repartimiento de la huerta de Murcia pude dar a conocer la entrega de sus tres cuartas partes, así como el número, ubicación, escala social, etc., de los pobladores que en ella se asentaron. En 1272 quedaba oficialmente una cuarta parte de ella en poder de sus dueños musulmanes, si bien conforme al pacto de Alcaraz y renovación de condiciones hecha en 1266, obligados al pago de las rentas pertenecientes al rey. Sucedería igualmente que por la imposición de la soberanía castellana fueron muchos los moros que emigraron abandonando sus tierras, y en estas circunstancias pudo hacer merced Alfonso el Sabio a sus tres moros orfebres y a otros pobladores de las tierras que habían quedado uagadas, si bien con carácter de donadío, al respetar esta parte de la huerta su carácter de zona musulmana.

Tenemos ahora la oportunidad de poder completar la repoblación cristiana de esta cuarta parte huertana, no entregada entonces, así como sus vicisitudes tiempo adelante, merced a documentos y diversos artículos publicados años después de mi estudio que directa o indirectamente afectan a este tema. Una nueva perspectiva y un paso adelante con la significativa apertura a posibilitar nuevas investigaciones que pudieran completar esta última fase del Repartimiento de la huerta de Murcia. Recordemos el proceso.

En el tratado de Alcaraz, firmado en 1243 se acordaba la pacífica implantación del protectorado castellano en el reino musulmán de Murcia, constituido entonces por un mosaico de señoríos independizados de débil reyezuelo que se mantenía en la capital. En el pacto se fijaron dos condiciones básicas: ocupación de las fortalezas y cobro de dos tercios de las rentas que percibían el rey y señores en sus respectivos ámbitos y jurisdicciones. En principio se concertaba y entendía la entrega pacífica de todo el reino, si bien quedaba un futuro incierto porque no todos los señores, de los señorios señoreados sobre si como dice la Crónica, enviaron sus representantes a Alcaraz e incluso algunos que así lo hicieron, después se negaron a cumplirlo.

De aquí que lo convenido y proyectado a realizar en plazo de cortos meses se extendiera a más de dos años, porque si la capital aceptó una realidad difícilmente insoslayable, no lo fueron así las principales poblaciones, temerosos sus señores de perder la autoridad y autonomía que habían logrado. Negativa a entrada de los castellanos que obligó a la presencia y amenaza de la hueste alfonsí, tal Orihuela en este mismo año y de Lorca en 1244 que, asediadas, acabaron aceptando lo capitulado en Alcaraz. No así Mula y 
Cartagena que se resistieron y combatidas hubieron de entregarse sin condiciones en 1244 y 1245 , por lo que quedaron bajo pleno dominio del soberano castellano.

En base de este tratado de Alcaraz, el infante don Alfonso, como heredero de Castilla iría entregando a diversos nobles de su hueste la tenencia de los principales núcleos de población en su doble concepto de posesión y seguridad de sus fortalezas, con el cobro de las rentas convenidas en el pacto, y respeto a los musulmanes en sus posesiones, religión, modos de vida, etc. En 1244, asegurado el reino de Murcia bajo dominio castellano y firmado el tratado de Almizra, por decisión real la tenencia se convertía en señorío, de lo temporal a definitivo ${ }^{1}$.

Tiempo adelante y sobre todo en 1257, en el transcurso de su permanencia en el reino más de seis meses, Alfonso $\mathrm{X}$ efectuó cambios e introdujo innovaciones que, sin quebrantar directamente el tratado de Alcaraz, si suponían modificaciones de la situación tendentes a un mayor control y castellanización del reino, así como al gradual asentamiento de pobladores cristianos. Fue así la creación del "concejo de Murcia la nueva", ubicado en donde tiempo después se crearía el barrio de San Juan y con entrega de cuatrocientas cincuenta tahúllas en el heredamiento de la Condomina para repartir entre sus pobladores por caballerías y peonías. Concedería igualmente diversos donadíos en lugares concretos de las huertas de Murcia y Orihuela, sin más alcance oficial entonces que el disfrute personal de sus rentas, pero significativo de la soberanía de Castilla en todo el reino.

Vencida la rebelión mudéjar en 1266 y para llevar a efecto la organización del reino Alfonso X hubo de superar el problema creado por la capitulación concedida por Jaime I a los moros de la capital. Tuvo de respetar parcialmente lo concertado pero conviniendo con los dirigentes de la Morería en una nueva orientación, que los mudéjares, tanto por la sujeción a que estaban sometidos como porque les favorecía, la aceptaron. Tal fue la división del término concejil, huerta y campo por mitad, con un trazado rectilíneo desde las montañas de Churra huerta y campo hasta los límites del concejo de Cartagena, y a la vez habilitándoles como núcleo urbano la totalidad del arrabal murado de la Arrixaca.

1 Torres Fontes, J., "Del tratado de Alcaraz al tratado de Almizra. De la tenencia al señorío (1243-1244)”, Miscelánea Medieval Murciana, XIX-XX, 1995-96, 53-65. 
Hacía así frente el rey Sabio al contradictorio problema que se le ofrecía: Necesidad de atraer población cristiana con la inmejorable perspectiva de casas en la ciudad y propiedades en la huerta y, a la vez, la opuesta, la de mantener la población mudéjar, imprescindible para la continuidad de los cultivos especializados, con producción intensa y variada en su huerta, no siempre apetecida o acostumbrada en la alimentación castellana.

No se ha explicado las razones de la adjudicación de cada parte a unos y otros. Si aguas arriba del Segura fue para los mudéjares por la relación directa de Arrixaca-huerta y multiplicidad de feraces minifundios, o por el contrario hubo otras razones económicas. Lo cual supuso el desalojo mudéjar de esta mitad y consiguiente emigración por otra parte. La elección por parte castellana no fue acertada, porque los nuevos pobladores, desconociendo técnicas y costumbres, no supieron mantener tierra y riego en las condiciones precisas. La falta de adecuado avenamiento dejaría parte de esta zona huertana convertida en almarjal. Basta recordar que de las diez alquerías entregadas en 1266 a la Iglesia a cambio de su primera dotación en maravedíes cuando fue restaurada en 1250, seis años después, en 1272 ya solo quedaban seis laborables.

En la zona mudéjar seguirían los mismos propietarios, quienes pagarían sus rentas indistintamente a uno y otro monarca por la existencia de donadíos. Es por ello que en el códice del Repartimiento, previa a la relación de cuadrillas y adjudicación de tierras, se especifiquen los donadíos existentes en la parte cristiana, pero no en la mudéjar, pese a que los hubo importantes desde el mismo año en que se establece la división del término concejil. Sería así el concedido a Abu Muhammad Abd Allah b. Ashkilula, hijo del arráez de Málaga, Abul Hasán Alí, quienes aliados con Alfonso X se mantenían en el interior del reino granadino haciendo frente a su monarca y pariente, AlAhmar, rey de Granada.

Este Ibn Ashkilula sería agraciado con un donadío de novecientas alfabas, el mayor de todos los conocidos en el Repartimiento y que suponían más de mil tahúllas en la parte adjudicada a los mudéjares. Tiempo después, en 1272, las necesidades de la repoblación exigirían nuevas tierras para atender las demandas de los pobladores y algunos quejosos de su suerte, como Obispo y Cabildo, que lograron mejorar, y por ello Alfonso X dispuso de la mitad de la parte asignada a los mudéjares, esto es, la situada a la derecha del Segura regada por la acequia mayor de Alquibla. 
Esta anexión crearía problemas, entre ellos el que parte de las novecientas alfabas de Ibn Alhkilula se encontraban en esta zona, por lo que hubo necesidad de cambiárselas. Así lo expresa el códice del Repartimiento: Era de mill et CCC et diez annos. Miercoles primer dia de junio touo el Rey por bien de dar cambio al arraez Aboabdille, fijo del arraez de Malega, LXX et VII alffabas et quarta en la parte de los moros por otras LXXVII alffabas et quarta que ante auia en Alualeja, lo que el rey mando partir a los cristianos, el mandogelas dar en estos logares que aqui seran dichos...en Acyhayrach...en las Tercias... Albocar... et dentro de la Arrixaca de los moros media alffaba... son LXXVII alffabas et quarta. Es entonces cuando en el Repartimiento, aparte de recoger esta porción del donadío de Ibn Ashkilula se añade: Agora diremos de los donadios que el Rey dio en renta de alffabas en los heredamientos que los moros an en Aljouff (Aljufía) que recudan a los herederos con los drechos et con las rendas que el Rey deuia auer ${ }^{2} \mathrm{Su}$ relación es:

$\begin{array}{ll}\text { Hugo de Anglerola } & 101 \text { alfabas } \\ \text { Aboabdille } & 72,2 \\ \text { Bernat de Centellas }^{3} & 12 \\ \text { Guillen dez Bruyll }^{\text {Bernat del Arábigo }} & 9,4 \\ \text { Abrahim, Ahmed, Mahomad } & 12 \\ \text { Caçim Anacax } & 24 \\ \text { Total } & 256,6 \text { alfabas }^{5}\end{array}$

2 Repartimiento de Murcia, Madrid, C.S.I.C., 1950, y Repartimiento y Repoblación de la huerta de Murcia en el siglo XIII, Murcia, 1990.

3 En la entrega del real a Bernat de Centellas, que lo había solicitado por no tener casas en Murcia, se dice que once alfabas eran catorce tahúllas. Relación tahúlla-alfaba que si no se puede generalizar para todas las tierras entregadas en donadío, ya que se trataba y así lo expresa que era un real, si cabe tener en cuenta esta equivalencia, indicativa del alto valor de estas tierras. Vid. J. Torres Fontes: "Medidas de valoración y superficie en el Repartimiento de Murcia”, en Repartimiento y Repoblación ..., 53-65.

4 Solo fue cambio de tierras, porque las suyas no tenían arbolado.

5 En el Repartimiento se incluye a Esteban Andreo, y se atiende su solicitud de cambio de 128 tahúllas que tenía en ésta parte de Aljufía, por otras en la zona cristiana de Alquibla. Así se hizo, pero sin contestación a su petición de seguir disfrutando de las rentas que, como donadío, había tenido. 
Los topónimos que se indican al señalizar los linderos de estos donadíos permiten fijarlos en un mismo espacio del regadío de la acequia mayor de Aljufía, el comprendido entre la Arrixaca, Puerta de Molina, carreras de Alhidaxar, Monteagudo Axufa y Molina. acequia de Cara (Carabija ?), -se cita una calleja Zocac Axufa-, así como otros topónimos: Albocar, Asanacat, Açyharich, alqueria de Hidaxar, Forçe Çagar, Alçoz, etc.

Igualmente hay que tener en cuenta que en los donadíos otorgados a los tres orfebres moros del rey y las dieciocho alfabas concedidas a Caçim Anaxar se dice que estaban uagadas....aquellos moros cuyas fueron son ydos de la terra. Mención interesante pues confirma la efectividad de las tres emigraciones musulmanas detestadas hacia Granada, conocidas y deducidas en el transcurso de los veinte últimos años del reinado de Alfonso X.

Entre los que conservaban bienes en esta parte de la huerta se hallaba el propio Muhammad Abd Allah Ibn Hud, titulado rey de los moros de la Arrixaca, quien de sus bienes propios concedió a Pedro Sánchez, su escudero, tres heredamientos; alfaba y media en Asanacat; cuatro y cuarta que lindaban con tierras que fueron de los arees de Malaga, y siete tahúllas cerca de la Puerta de la Arrixaca. Donación confirmada por Alfonso X en 2 de marzo de 1277 y que a petición de Alí Abul Hacen Ibn Hud, hermano y sucesor de Muhamad, volvía a hacerlo en 7 de enero de $1280^{6}$.

Esta mención "fueron" de los arraeces de Málaga de la carta real de 1277 señala la ruptura anterior de la alianza de Alfonso X y Ashkilulas, como también el que las novecientas alfabas que le había concedido en 1266 no tenían ya efectividad. Sería por ello que en este mismo año 1277, el 3 de junio, las otorgara Alfonso X al monasterio de Santa María la Real que acababa de fundar en Murcia. Por la información recibida pudo saber que gran parte de ellas habían sido concedidas por los partidores a nuevos pobladores o a incrementar lo de otros ya heredados. De aquí su decisión de recobrarlas en su totalidad. Y primera orden la de secuestrar y recobrar las tahúllas de quienes le habían sido traidores y deservido y cita concretamente los nombres de Alejandro de Loaysa y Bernad Dodena. En cuanto al resto de los pobladores heredados en dichas tierras, su disposición fue que se les diera equivalencia en zonas huertanas no entregadas. Se cita una condesa a quién

6 CODOM, II, 96-7 y 103. 
se debía compensar las treinta alfabas que tenía en ésta zona por otras tantas en Beniscornia, en el alhoz perteneciente a la mezquita ${ }^{7}$.

Desde 1279 a 1284 transcurre un tiempo del que nada sabemos en estas tierras y queda la duda si la decisión de Alfonso X de potenciar y proporcionar futuro a la Orden de Santa María de España en su vertiente religiosa del monasterio de Santa María la Mayor de Murcia tuvo plena efectividad. Sólo nos quedan dos cartas propias relativas a este Monasterio de los años $1280 \mathrm{y}$ 1281. Esta última es la concesión de un real al sobrino del abad del Monasterio cabo la alqueria de Hidaxar, que había sido de Alí, moro de la reina, con casas y valorado en catorce alfabas y media; real ubicado entre dos carreras y heredamientos pertenecientes a la mezquita de Beniscornia ${ }^{8}$.

En 1282 se alteró totalmente el orden en Castilla con la proclamación del infante don Sancho y deposición oficial de Alfonso X. Iba a lograr don Sancho el reconocimiento de la nobleza y la mayor parte de Castilla, con excepción muy señalada de Sevilla y Murcia capital. El infante don Sancho no sólo mantuvo su rebeldía frente a su padre gobernando los reinos que le reconocieron, sino contradiciendo cuanto pudo las decisiones paternas. Así fue en el reino de Murcia. Contaba con la fidelidad e información del obispo Diego Martínez Magaz, quien muy pronto sería pagado por su afiliación política. A la concesión al monasterio de Santa María en paridad con la Orden de Santa María de España de las salinas de Orihuela en 1277, don Sancho las concedía en 1283 viviendo su padre, al concejo de Orihuela; de igual modo los molinos, noria y heredamientos junto al alcázar, en aquel logar que los moros solian dezir Axerca e despues quando fue poblado de christianos llamaron Murcia la nueva, donada por el rey Sabio al Monasterio en 1277, es también en 1283 cuando don Sancho la concedía a la Iglesia y Obispo. Mas

7 Una condesa que cabe identificar como la esposa del conde don Dionís, ya fallecido en 1271. Pertenecía al amplio núcleo cortesano de procedencia húngara que acompañaron a la reina doña Violante cuando contrajo matrimonio con Jaime I. El conde don Dionís y su esposa fueron padres de Amor -heredado en el Repartimiento de Orihuela- y de Gabriel. La Condesa viuda y sus hijos recibieron generosas ayudas de Jaime I y Pedro III. Conocido es que muchos de ellos se diseminaron por Castilla con la ayuda de la reina doña Violante, especialmente Murcia y Andalucía (Torres Fontes, J., Repartimiento de Orihuela, Murcia, 1988, I y LX, así como en el Repartimiento de Murcia).

8 Osma, 11-III-1281. Torres Fontes, J., "El monasterio cisterciense de Santa María la Real de Murcia". Medievo Hispano. Estudios in memoriam del prof. Derek W. Lomax, Madrid, 1995, 369-383. 
tardío, ya en su reinado, Sancho IV atendía en 1290 la solicitud de Loaysa y ordenaba la devolución de sus bienes ${ }^{9}$.

El monasterio de Santa Maria la Mayor, la gran ilusión de Alfonso X, mantenida a su hora postrera al disponer en su testamento, de tener, de ser posible, en el su sepultura, prácticamente "desaparece". Todas las concesiones alfonsíes serían anuladas y más las relativas a Murcia, donde obispo y cabildo se adueñaron de ellos, aunque es posible que no pudieran hacer efectiva la disposición de Sancho IV hasta la muerte del rey Sabio.

No es hasta 1286 cuando estas tierras huertanas de la zona de Aljufía, reservada a los moros, vuelven a ser objeto de disposiciones reales. Ya no se habla de las novecientas alfabas del arráez de Málaga y después del monasterio de Santa María sino de una tercera parte, un tercio, Lo que parece indicar que los "reintegros" ordenados por Alfonso X en 1277 no tuvieron plena efectividad. Ahora Sancho IV hace mención de un tercio de las alhabas, si bien en los heredamientos que los monjes auien en Murcia ${ }^{10}$, y de las que hacía donación a su Copero Fernán Núñez.

Cinco años mantuvo Fernán Núñez este donadío. Ningún otro interés tenía en el reino de Murcia; la distancia de su tierra gallega era grande y las rentas que pudiera obtener no debían ser muy atractivas, por ello buscó medio de enajenarlas, pero la prohibición inserta en la donación de no vender a Iglesia ni Orden, le llevaría en negociaciones que sólo encontró propicia en la Orden de San Juan, hasta obtener en $1291^{11}$ nueva concesión de Sancho IV de este tercio con revocación de sus cláusulas restrictivas, lo que permitiría la venta a Orden militar e incluso indicando el propio monarca su preferencia que fuera con la Orden de San Juan. Otra innovación en esta segunda carta concesionaria es que ya no se mencionan las alfabas que habían sido de los monjes, pues era cosa pasada y olvidada, sino que auian sido de los moros $^{12}$.

En el documento de compra de la Orden de San Juan al Copero real se especifican las condiciones atractivas para Fernán Núñez ${ }^{13}$ y poco más, pero

9 Madrid, 27-XI-1290. CODOM, IV, 102.

10 Serra Ruiz, R., "La Orden de San Juan de Jerusalén en el reino de Murcia", incluido en Estudios de historia de Murcia, Murcia, 1981, 945-991.

11 Intermedio se conocen tres cartas sobre esta componenda para salvar las prohibiciones de la primera donación (Serra, 68-86).

12 Serra, 82. Que los moros auien en Murcia.

13 Seis mil maravedíes, más mil maravedíes anuales en tanto vivieren don Fernán o su mujer. 
en ambas donaciones reales, 1286 y 1291 se mantienen emparejadas con un mismo tenor, salvo leves variantes en sus deficientes transcripciones de los traslados, nombres, topónimos y alfabas, asumibles. Se relacionan cincuenta y seis moros (44 hombres y 12 mujeres), que "fueron" anteriores propietarios, con indicación minuciosa del valor en alfabas de cada parcela. La suma total es de doscientas ocho alfabas, dos ochavas de ochava y seis ochavas de ochava de ochava (208-0-2-6), A estas heredades se agregan tres topónimos: Benihuraite, Alfereç y Algualeja que cayeron en su parte, cuya valoración en alfabas no se incluye, así como participación en tres reales, éstas si cifradas.

Dado que este tercio de alfabas, primero de los monjes y después de los moros, eran sin duda la tercera parte de las famosas novecientas alfabas del hijo de arráez de Málaga, es por tanto posible cifrarlas en trescientas alfabas.

$\mathrm{Si}$ a estas trescientas alfabas restamos las 208-0-2-6 que contabilizamos en las cincuenta y seis heredades que tenían los moros, restan noventa y una alfabas, siete ochavas, cinco ochavas de ochava y dos ochavas de ochava de ochava (91-7-5-2), cabe deducir que éstas alfabas fueran el valor de los tres topónimos no valorados en ambos documentos reales: Banihuraite o Banhurait, Alfereç o Alferçe y Algualega. Tres topónimos, especialmente el de Algualeja, que puede ser identificados y calculada su extensión, para deducir su posible valoración. Otros topónimos por identificar, pero de posible localización, podrían completarlo todo ${ }^{14}$.

A esta cuestión y consiguiente deducción, se suma otra de semejantes características. Tiempo adelante, cuarenta años más tarde, en 1331 fray Fernando Rodríguez de Valbona, prior de la Orden del Hospital de San Juan en Castilla y León, se interesó por conocer los bienes, situación y rentas que la Orden tenía en Murcia. Dio orden a Martín Gallego, su alcaide del castillo de Calasparra, que contratara un Notario para que le hiciera relación de todos los censatarios en Murcia, de cada uno quantas taffullas tiene e por quanto prescio e a que plaços pagan. Añadía instrucciones para en caso que se vendieran algunas tahúllas se hiciera saber que la fadiga era de treinta días y el laudemio del diez por ciento de la vendida. Se advierte un desconocimiento total y un propósito de renovación y puesta al día, porque se agrega la

14 Son así los reales Dolenalveal o Readonal Voçet; tierra blanca de Cuferah, Cuferag, alqueria de Fidaxat o Fiday, real de Abenfoçin o Aben Goçin, real de Aben Halron o Berçançon. 
obligación de cada censalero de plantar trece arboles en cada taffulla que tomaran; árboles que diesen fruto o para cambiarlos; de igual forma concretaba el pago de los censos, mitad en San Juan, mitad en San Miguel.

Contamos así con otra relación de quienes usufructuaban estas tierras. Ya no hay nombres de moros sino de cristianos, y las heredades no se valoran por alfabas, sino que se miden por tahúllas, y se especifican las cantidades que pagaban o debían pagar los censatarios. Las cincuenta y seis heredades anteriores se reducen ahora a treinta y seis, sin duda de mayor tamaño y con otra clase de cultivos. De su contexto se precisa que la Orden no se había preocupado por sus posesiones y, por lo que parece mal administradas, pues se dice que el censalero solo cobraba un huerto de cincuenta tahúllas y, sobre todo que el representante del Prior en el reino de Murcia era su alcaide de la fortaleza de Calasparra, lo que suponía permanencia y lejanía, pero además se nos dice que era vecino de Cieza. Entre Calasparra y Cieza en su vivir cotidiano, no sería muy frecuente la estancia en Murcia de Martín Gallego y menos en las heredades huertanas de la Orden. Además, hay que recordar que durante largo tiempo fueron años extremadamente difíciles y que afectaría todos: Guerra civil en el reino en la mantenida contienda Murcia-Don Juan Manuel; guerra de Granada; sequías continuadas, hambrunas, baja demográfica, casas derruidas en la Arrixaca y su despoblación, tal como la certificaba dos años antes el propio Alfonso XI: La Arrixaca es logar que esta todo despoblado et se fazen y muchos males; tierras no laboradas y abandono de cultivos como sucedía en esta zona huertana de la Orden de San Juan, tal es el caso de seis taffullas de tierra que son en Algualeja, huerta de Murcia, riua el rio e porque estan riua el rio ninguno las quiere asensar.

Una muestra de cual era la situación de la huerta en esta primera mitad del siglo XIV, antes de la Peste Negra, la ofrece la variedad de tierras dependientes del riego, ubicación y extensión. Dieciséis de estas heredades pagaban o se les impone un censo superior a diez maravedíes tahúlla-año. De ellas destacan las de regadío de las filas o acequias de Pontel y "Nada", con $14 \mathrm{~m} / \mathrm{t}$, que baja en la fila de Erhaues a $10 \mathrm{~m} / \mathrm{t}$. También con $14 \mathrm{~m} / \mathrm{t}$ las situadas en la Puerta de Molina, y en cambio bajan, quizá también por su proximidad al río, las de Algualeja en $12 \mathrm{~m} / \mathrm{t}$. En cambio las más extensas, como las 34,4 de Bidayer su censo era de $5 \mathrm{~m} / \mathrm{t}$ y otras a tres y cuatro maravedis tahúlla. En la fila de Nada, con 19 tahúllas y a razón de $14 \mathrm{~m} / \mathrm{t}$ se incluyen dos matrimonios, sin duda familiares por razón del riego y riqueza de estas tierras. En cambio, un solar de casa a la entrada a Murcia el censo era 
tan solo 3 maravedíes anuales, que corrobora las afirmaciones de Alfonso XI dos años antes.

Como detalle curioso señalamos que sistemáticamente cuando los censatarios son matrimonio, se incluyen los nombres de marido y mujer, pero el de éstas siempre con tratamiento indistintamente dueña o dona, y sin titulación alguna los hombres. Y en este mismo orden de cosas, recogemos los nombres femeninos: Agueda, Andrea, Antonia, Avrsuz, Bartolomea (dos), Belenga (dos), Berenguera, Bencital, Bernarda, Brígid, Constanza, Elvira, Francisca, Gracia, Juana, Juana de Alça, Leonor, Lorenza y María (cinco).

La suma total de tahúllas, salvo error, son 391, cifra que sensiblemente nos acerca a su conexión o identificación con las trescientas alfabas o tercio de la donación de Sancho IV a su Copero Fernán Núñez, siempre superior el número de tahúllas al de alfabas. También nota diferencial y síntoma de los tiempos, es que si la venta de Fernán Núñez a la Orden fue de seis mil maravedíes, más mil anuales en tanto viviera él o su mujer, aquí la suma total de censos -si pagaban todos- no parece que sobrepasaran los tres mil maravedíes anuales. Dos tiempos, distanciados en unos treinta años, cuya diferencia esta en razón del empeoramiento general que en todos los órdenes de la vida se manifiesta en Castilla en esta primera mitad del siglo XIV y que con un lento renovar comienza a cambiar en su segunda mitad.

Estos censales de la Orden de San Juan, con abundante número de topónimos identificables, así como la ubicación de las tahúllas, las cuales, unidas a las relaciones anteriores de "tiempo de los moros", en su conjunto ofrecen amplias posibilidades a quien pueda interesar para completar estos datos que ofrecen los documentos. 


\section{APÉNDICE}

Alfabas (A). - Ochavas (0). - Ochavas de ochavas (00). Ochavas de ochava de ochava $(000)$

$$
\begin{array}{llll}
\text { A } & 0 & 00 & 000
\end{array}
$$

Real Dolenalveced (Readonal Voçet )

Payçeti (Parçeri)

Aboabdille Aben Hotab

Aben Alsoff (Aben Alhaf)

Alqua deyssi (Alhayssi)

Aben Massid (Aben Nasid)

Aben Morabit (Aben Mouarit)

Abu Almunadan

Aben Nagab

Alcaizati

Rocaque (Roçaq)

Jusali (Ynsali)

Aben Galib (Bengali)

Alfaibanlti

Mahomad Aben Ali Abentbit

(Abrahim Albaçeat)

Abrahim al Nassar

Aben Camel (Aben Calmet)

Aben Bayren (Aben Hairen)

$\begin{array}{llll}3 & 5 & 3 & 5 \\ 4 & 2 & 7 & 5 \\ 3 & 5 & 3 & 1 \\ 2 & 4 & 3 & 6 \\ 4 & 0 & 6 & 5 \\ 2 & 1 & 0 & 4 \\ 3 & 0 & 7 & 0^{1} \\ 4 & 5 & 6 & 0 \\ 7 & 0 & 4 & 7 \\ 4 & 2 & 0 & 0 \\ 6 & 2 & 0 & 0^{2} \\ 2 & 1 & 0 & 1 \\ 2 & 6 & 7 & 4^{3} \\ 2 & 1 & 3 & 1^{4}\end{array}$

Aben Nesi Al Salafq (Aben

Nehin Alhalaff)

Aben Mufadal

$\begin{array}{llll}0 & 4 & 5 & 2 \\ 2 & 7 & 6 & 7^{5} \\ 5 & 3 & 3 & 0 \\ 1 & 2 & 2 & 3 \\ & & & \\ 6 & 2 & 5 & 0 \\ 5 & 3 & 3 & 6\end{array}$

1 En la Segunda 3-7-7-7.

2 Tierra blanca.

3 Intercambiados Aben Galib y Alfaibanlti y está solo en la segunda.

4 Solo en la segunda.

5 En la segunda 5-3-3-3. 
Abu Cahadet

Arráez Albugeis (Auah Abulgais)

$\begin{array}{llll}7 & 4 & 4 & 6\end{array}$

El moro Acaracani (El moro Haraçoni)

$\begin{array}{llll}4 & 0 & 2 & 0\end{array}$

Sadat (Sahai)

Abincabra (Aben Cauia)

Abrahenabegi (Abrahim Albegi)

$\begin{array}{llll}11 & 2 & 6 & 3\end{array}$

Mahomat Altagari Abegarid (M. Abogari)

Fatima, hija de Aben Ali

$\begin{array}{llll}9 & 3 & 3 & 1^{6}\end{array}$

Rahabi (Rauani)

Aben Naufal

Ali Mudiif (Ali Mudruff)

Ali Aben Mutmien (Ali Aben Nutinem)

Axa, hija de Algayar

$\begin{array}{llll}5 & 7 & 0 & 0\end{array}$

$\begin{array}{llll}6 & 5 & 2 & 2\end{array}$

Muhiria, hija de Aben Qicet (Muhina, hija de Aben Hiçet)

Ali Alguidi (Ali Algidi)

Hamet Alcaeçar (Amed Alcacar)

$\begin{array}{llll}1 & 2 & 0 & 6^{7}\end{array}$

$\begin{array}{llll}2 & 2 & 0 & 0\end{array}$

$\begin{array}{llll}1 & 0 & 7 & 3\end{array}$

$1 \quad 0 \quad 4 \quad 6$

$\begin{array}{llll}4 & 2 & 6 & 4\end{array}$

$\begin{array}{llll}2 & 7 & 2 & 3\end{array}$

$\begin{array}{llll}3 & 1 & 6 & 5\end{array}$

$\begin{array}{llll}1 & 5 & 6 & 0 \\ 1 & 0 & 0 & 0 \\ 3 & 2 & 0 & 5\end{array}$

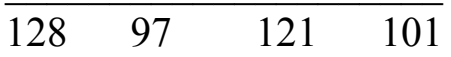

A $\quad 0 \quad 00 \quad 000$

Ali Alssihegi (Ali Acinhegi)

Mahomat Aben Zalama (Çalama)

Yuçat Algirab (Y. Alguiad)

Abdalla Abenhit (Abdalla Abenvit)

$\begin{array}{llll}4 & 0 & 1 & 6 \\ 1 & 0 & 4 & 0 \\ 0 & 6 & 0 & 2^{8} \\ 2 & 1 & 2 & 1\end{array}$

Ali Aben Muçe Alcauaç (Ali Aben

Muccalcarrat)

Mahomat Alarrac (M. Albarrat)

Assavda (Alssandudal)

$\begin{array}{llll}2 & 3 & 4 & 0 \\ 1 & 7 & 4 & 0 \\ 4 & 1 & 2 & 7\end{array}$

6 En Cufferag ó Cufferah tierra blanca.

7 En la alquería de Fidaxat o Fidayah.

8 En la segunda 0-6-2-0. 
Obaceat Albarqui (Abeçara llorqui)

Mahomat Turniel (M.Turmel)

Negma, hija de Subaypar (Gegma, hija)

Iliad (Ydad)

Camet Albalaneit (Amet Abbalançid)

Yusef Alcamed (Yuçaff Alcamed)

Mahomad Aben Macar

Amelealcaffar (Amet Alçafor)

Mahomat Abeluelto (Abeltorit)

Ali Alturani

Nagma, hija de Ali Altarrab Alcarrab

Abrazen Aben Mubaxir (Abrahim Aben Muharrin)

Açan Aber Abi Aben Teuir (Haçan Aben Ali Abentebit)

Sabet Alcabata (Caueta Alcaboca)

Yucaf Abu Aladib (Yucaf Abnaladib)

Yahie Almazmoli (Yahic Almahmoeli)

Real Aben Gocim

Real Berçançon (Real Aben Haron)

$\begin{array}{llll}2 & 6 & 3 & 6 \\ 0 & 3 & 2 & 3 \\ 0 & 4 & 0 & 6 \\ 4 & 0 & 3 & 2 \\ 0 & 2 & 0 & 0 \\ 1 & 3 & 1 & 0 \\ 0 & 6 & 1 & 4 \\ 1 & 5 & 1 & 0 \\ 2 & 7 & 6 & 79 \\ 0 & 6 & 1 & 4 \\ 1 & 7 & 6 & 4\end{array}$

$\begin{array}{llll}4 & 6 & 0 & 7\end{array}$

$\begin{array}{llll}1 & 3 & 4 & 7 \\ 0 & 6 & 1 & 5 \\ 4 & 5 & 0 & 0 \\ 3 & 3 & 7 & 6 \\ 3 & 5 & 4 & 5 \\ 12 & 7 & 1 & 7\end{array}$

\begin{tabular}{llll}
\hline \hline 52 & 102 & 5 & 89 \\
128 & 97 & 121 & 101 \\
& & & \\
\hline 180 & 199 & 179 & $190: 8$ \\
& & & \\
\hline $280-0$ & -2 &
\end{tabular}

9 Solo en la segunda. 